\title{
Benzalkonium Chloride-Preserved Anti-Glaucomatous Eye Drops and Their Effect on Human Conjunctival Goblet Cells in vitro
}

\author{
Anne Hedengran a, b Xenia Beguna Olivia Müllertz ${ }^{a} \quad$ Zaynab Mouhammad $^{a}$ \\ Rupali Vohraa, c Jeffrey Bair ${ }^{d}$ Darlene A. Dartt ${ }^{d}$ Barbara Cvenkel ${ }^{e}$ \\ Steffen Heegaard $^{b, f}$ Goran Petrovski $^{9}$ Miriam Kolko $^{a, b}$ \\ aDepartment of Drug Design and Pharmacology, University of Copenhagen, Copenhagen, Denmark; \\ ${ }^{b}$ Department of Ophthalmology, Copenhagen University Hospital, Rigshospitalet-Glostrup, Glostrup, Denmark; \\ 'Department of Veterinary and Animal Sciences, University of Copenhagen, Copenhagen, Denmark; dSchepens Eye \\ Research Institute, Massachusetts Eye and Ear, Department of Ophthalmology, Harvard Medical School, \\ Boston, MA, USA; 'Department of Ophthalmology, UMC Ljubljana, Ljubljana, Slovenia; 'Department of Pathology, \\ University Hospital Rigshospitalet, Copenhagen, Denmark; ${ }^{9}$ Department of Ophthalmology, University Hospital \\ Rikshospitalet, Oslo, Norway
}

\section{Keywords}

Goblet cells · Glaucoma · Benzalkonium chloride ·

Anti-glaucomatous treatment $\cdot$ In vitro study

\begin{abstract}
Introduction: Most intraocular pressure (IOP)-lowering eye drops are preserved with benzalkonium chloride (BAK). This can increase side effects and decrease adherence. Particularly, damage to the mucin-producing conjunctival goblet cells may be an issue due to instability of the tear film. We aimed to investigate the effect of IOP-lowering eye drops preserved with BAK on cultured human conjunctival goblet cells. Methods: Eye drops Brimonidine Tartrate Teva (BT) with 0.005\% BAK, Dorzolamide Stada (DS) with $0.0075 \%$ BAK, Optimol (OP) with $0.01 \%$ BAK, and Latanoprost Teva (LT) with $0.02 \%$ BAK were included. Human primary cultured goblet cell survival was evaluated using a lactate dehydrogenase assay on human goblet cells after treatment
\end{abstract}

karger@karger.com www.karger.com/bmh

Karger $\stackrel{\text { ' }}{5}$

GOPEN ACCESS
(C) 2021 The Author(s)

Published by S. Karger AG, Basel

This is an Open Access article licensed under the Creative Commons Attribution-NonCommercial-4.0 International License (CC BY-NC) (http://www.karger.com/Services/OpenAccessLicense), applicable to the online version of the article only. Usage and distribution for commercial purposes requires written permission. for $30 \mathrm{~min}$ and $6 \mathrm{~h}$ with the different anti-glaucoma drug formulations. Results: All eye drops examined, except BT, reduced goblet cell survival. The impact of eye drops on goblet cell viability was correlated with the time of exposure as well as to the concentration of BAK. After $30 \mathrm{~min}$ of exposure, cell viability was $93 \%$ for BT $(0.005 \%$ BAK; $p=$ $0.93), 71 \%$ for DS $(0.0075 \%$ BAK; $p=0.067), 70 \%$ for OP $(0.01 \%$ BAK; $p=0.054)$, and $69 \%$ for LT $(0.02 \%$ BAK; $p=$ $0.022)$, and exposure for $6 \mathrm{~h}$ reduced cell survival to $74 \%$ for $\mathrm{BT}(p=0.217), 52 \%$ for DS $(p=0.011), 34 \%$ for OP $(p=0.017)$, and $31 \%$ for LT ( $p=0.0007)$. Conclusion: LT, OP, and DS reduced human goblet cell survival in a time-dependent manner. BT did not affect goblet cell survival. Cell survival was correlated with the BAK concentration in the eye drops making $0.02 \%$ BAK-preserved LT most toxic and $0.005 \%$

Anne Hedengran and Xenia Begun contributed equally to the current study and are considered co-first authors.
Correspondence to:

Miriam Kolko, miriamk@sund.ku.dk 
BAK-preserved BT least toxic. Based on the present study, decreasing BAK in eye drops for chronic use seems important to reduce damage to the goblet cells. However, future studies are needed to further explore this finding.

(C) 2021 The Author(s)

Published by S. Karger AG, Basel

\section{Introduction}

Primary open-angle glaucoma (POAG) affects approximately $3 \%$ of the world's population aged $40-80$ years [1]. POAG is an optic neuropathy and is characterized by a progressive degeneration of the innermost retinal neurons, the retinal ganglion cells. The etiology of POAG is not known, but an elevated intraocular pressure (IOP) is a proven risk factor [2]. IOP can be lowered with eye drops, laser treatment, or surgery, with the far most common treatment being eye drops. Eye drops lower IOP by decreasing aqueous humor production and/or by increasing outflow. Eye drops available at Danish pharmacies that decrease aqueous humor production include beta-adrenoceptor blockers (BB), carbonic anhydrase inhibitors (CAI), and alpha-2-receptor agonists (AA), with AA also increasing uveoscleral outflow. Prostaglandin analogs (PG) increase the outflow. In addition to the eye drops listed, the muscarinic eye drop, pilocarpine, increases outflow by inducing miosis. Due to the incurable nature of POAG, most patients require lifelong treatment. In Denmark, $47 \%$ of glaucoma patients use PG monotherapy making PG the most frequently used glaucoma treatment [3], followed by $\mathrm{BB}, \mathrm{CAI}$, and AA. While most glaucoma patients are treated with monotherapy, $23 \%$ of Danish glaucoma patients are prescribed 2 or more preparations [3].

The available IOP-lowering eye drops cause substantial side effects. The most common side effects are burning, itching, redness, tearing, and blurred vision [4]. The same symptoms can be seen in patients with ocular surface disorders (OSD). The prevalence of OSD in an average population is reported to be approximately $15 \%[5,6]$, while the prevalence of OSD among glaucoma patients has been reported to be around 60\% [6].

Most side effects on the ocular surface can be related to a reduced quality of the tear film. The tear film consists of 3 layers: an inner layer of lubricating mucin; a middle layer of proteins, electrolytes, and water; and an outer layer of lipids [7]. Mucins are secreted from the conjunctival goblet cells and stabilize the tear film as well as protect the ocular surface from dryness. The goblet cells are present in the entire conjunctiva in clusters or individually. In the human conjunctiva, the highest density of goblet cells is found na- sally, and the cells reach partway down the apical surface of the stratified epithelium $[8,9]$. Goblet cells are also present in the gastrointestinal, urogenital, and respiratory tracts. The development of goblet cells and hence the production of mucins has been shown to depend on the epithelial transcription factor SPDEF [9]. In SPDEF null mice, increased fluorescein staining of the cornea, inflammatory cells in the conjunctival epithelium, tear volume, and accumulation of debris have been found [7]. These findings substantiate the important role of goblet cells and their mucins in protecting the health of the ocular surface.

Besides the branded variants, multiple preserved AA, CAI, PG, and BB generics are available, and the market is further expanding with preservative-free eye drops. Little is known about the effect of eye drops on the ocular surface, and the vast number of different eye drops is confusing to patients as well as to ophthalmologists. In Denmark, preserved eye drops are typically prescribed due to increased durability and lower price.

It has previously been hypothesized that preservatives are necessary for penetration of the active drug. This hypothesis has, however, since been rejected [10-12]. The most commonly used preservative is benzalkonium chloride (BAK), a quaternary ammonium compound. Eye drops preserved with BAK are known to cause more damage to the human ocular surface as well as the human corneal and conjunctival cells compared to eye drops containing the preservatives, polyquaternium-1(PQ1) and SofZia, or even better preservative-free eye drops $[13,14]$. The effect of BAK on human goblet cells, however, needs more investigation, as goblet cells may be of particular importance in the development of OSD in glaucoma patients.

The current study compares the effect of AA, CAI, BB, and $\mathrm{PG}$ eye drops on human conjunctival goblet cells. The eye drops included represent 4 multidose eye drops available in a glaucoma clinic in Denmark, and each contains different percentages of BAK. The advantage of this study is that it was performed on human goblet cells making it more clinically relevant than studies on animal models. We have successfully cultured goblet cells from donor tissue and developed purified cultures due to fibroblast removal.

\section{Materials and Methods}

\section{Treatments}

Anti-glaucomatous treatments included the AA Brimonidine Tartrate Teva (BT) (brimonidine tartrate $2 \mathrm{mg} / \mathrm{mL}$ and $0.005 \%$ BAK; Teva Pharmaceutical Industries Ltd., Petah Tikva, Israel), the CAI Dorzolamide Stada (DS) (dorzolamide $20 \mathrm{mg} / \mathrm{mL}$ and 0.0075\% BAK; STADA Arzneimittel AG, Bad Vilbel, Germany),
Hedengran et al. 
the BB Optimol ${ }^{\circledR}$ (OP) (timolol $5 \mathrm{mg} / \mathrm{mL}$ and $0.01 \%$ BAK; Santen Pharma AB, Solna, Sweden), and the PG Latanoprost Teva (LT) (latanoprost $0.05 \mathrm{mg} / \mathrm{mL}$ and $0.02 \%$ BAK; Teva Pharmaceutical Industries Ltd., Petah Tikva, Israel). All are produced as multidose vials.

\section{Cultivation of Goblet Cells}

Conjunctival tissue was obtained from human donor eyes from the eye bank, Department of Ophthalmology, Oslo University Hospital. The protocol complied with the Declaration of Helsinki and was approved by the Danish National Committee on Health Research (H-17007902) and the Norwegian Regional Committees for Medical and Health Research Ethics (REK: 2013/803). No data on donors were recorded as a control for each donor was included in all assays. Goblet cell cultivation is based on the work by Shatos et al. [15]. Conjunctival tissue was stored at $5^{\circ} \mathrm{C}$ in CorneaMax ${ }^{\circledR}$ (CMXSTO01F; Eurobio, Les Ulis, France) until cultivation. For cultivation, the tissue was dissected into $2 \times 2 \mathrm{~mm}$ pieces and placed into a 6-well culture dish. Immediately after 3-4 drops of culture medium (RPMI medium 1640 1X [32404-014; Gibco, Life Technologies, Waltham, MA, USA], 10\% [vol/vol] FBS [10270106; Gibco, Life Technologies, Waltham, MA, USA], 1\% [vol/vol] penicillin/streptomycin [15140-122; Gibco, Life Technologies, Waltham, MA, USA], 1\% [vol/vol] nonessential amino acid solution [M7145; Sigma-Aldrich, St. Louis, Missouri, USA], 1\% [vol/ vol] 1 M HEPES [15630-080; Gibco, Life Technologies, Waltham, MA, USA], 1\% [vol/vol] L-glutamine [25030-024; Gibco, Life Technologies, Waltham, MA, USA], and 1\% [vol/vol] sodium pyruvate [11360-039; Gibco, Life Technologies, Waltham, MA, USA]) were added per tissue piece, the plates were kept in an incubator at $37^{\circ} \mathrm{C}, 5 \% \mathrm{CO}_{2}$. For the following 3 days, 3-4 drops were added per tissue piece. Thereafter, the medium was changed every other day, adding $1 \mathrm{~mL}$ of medium. Routinely, the cells were checked employing microscopic visual examination with a light microscope to monitor growth of fibroblasts. In case of fibroblast growth, the fibroblasts were removed by scraping and the well rinsed with culture medium. After 14 days of cultivation, the goblet cells were trypsinized. Trypsinization was implemented with 1M EDTA (E5134; Sigma-Aldrich, St. Louis, Missouri, USA) in PBS, $0.48 \mathrm{~mm}$ versene (15040-033; Gibco, Life Technologies, Waltham, MA, USA), and 0.25\% (wt/vol) trypsin (T4799; SigmaAldrich, St. Louis, Missouri, USA). After trypsinization, cells were rinsed with medium containing $10 \%$ FBS serum, which inactivates trypsin. Finally, cells were pelleted, resuspended in medium, and seeded into 96 -well plates with a density of $25,000 \mathrm{cells} / \mathrm{cm}^{2}$. The cells were incubated for an additional $4-5$ days at $37^{\circ} \mathrm{C}$ before further experiments.

\section{Measurement of Goblet Cell Survival}

Conjunctival goblet cell survival was determined with a lactate dehydrogenase (LDH) assay (MAK401; Sigma-Aldrich, Shiga, Japan) used after treatment of cells. This assay measures the amount of LDH, a cytoplasmic enzyme, release from the cells. Goblet cells were exposed to BT, DS, OP, or LT diluted 1:7 in medium (volume $200 \mu \mathrm{L}$ ) for $30 \mathrm{~min}$ or $6 \mathrm{~h}$ in an incubator at $37^{\circ} \mathrm{C}$ and $5 \% \mathrm{CO}_{2}$. As the control, cells were treated with basal culture medium. After the treatment, the medium was changed, and the cells were left in the fresh medium for an additional $20 \mathrm{~h}$ before measurement of $\mathrm{LDH}$ release. The medium was removed and centrifuged at 500 rpm for $10 \mathrm{~min}$. Each supernatant was transferred to a corre-

Effect of Anti-Glaucomatous Drugs on Goblet Cells sponding well in a new plate. To measure the amount of $\mathrm{LDH}$ remaining in the cells, $200 \mu \mathrm{L}$ of $1 \%$ Triton-X (1001325622; Sigma-Aldrich, St. Louis, Missouri, USA) was added to each well in the original plate and incubated for $10 \mathrm{~min}$ at room temperature (RT). Plates were centrifuged, and each supernatant was transferred to a corresponding well. LDH solution was added and incubated for 3-15 min at RT; 1M HCL was added to each well, bubbles were removed, and the plates were read at $490 \mathrm{~nm}$ on the SpectraMax i3X multi-mode microplate reader (Molecular Devices, San Jose, CA, USA). Cell survival was assessed as the ratio between $\mathrm{LDH}$ release prior to membrane permeation by Triton-X and total LDH. Percentage compared to control was calculated. Cell survival was analyzed on at least 3 cell cultures from different donors.

\section{Measurement of Eye Drop $\mathrm{pH}$ and Osmolality}

Measurements were performed in triplicate on 3 containers of each type of eye drop. Measurements were performed promptly to reduce any contact with atmospheric air and thereby prevent any chemical reactions. The $\mathrm{pH}$ of each drop was measured with a calibrated standard laboratory $744 \mathrm{pH}$ meter (Metrohm; Nordic ApS, Herisau, Switzerland) at RT. Osmolality was measured using freezing point depression (Osmomat 3000; Gonotec, Berlin, Germany).

\section{Statistical Analysis}

Statistical analyses were performed with GraphPad Prism version 8.0.0. All statistical comparisons with control and in between eye drops were made with ordinary one-way ANOVA multiple comparisons (Tukey's multiple comparisons test). All values are expressed as mean. Significant outliers were eliminated prior to analyses. A $p$ value $<0.05$ was considered significant. Normal distribution of data was confirmed through QQ-plots.

\section{Results}

\section{Effect of BAK-Containing Eye Drops on Goblet Cell Survival}

Goblet cell survival was assessed by LDH assay on cell cultures from at least 3 different donors after exposure to diluted BT, DS, OP, and LT eye drops for 30 min or $6 \mathrm{~h}$. After a 30 -min treatment, only LT $(0.02 \%$ BAK) that contains the highest percentage of BAK had a significant effect on cell survival compared to control with a cell viability of $69 \%(p=0.022)$ (Fig. 1). After 6 h, LT (0.02\% BAK), OP $(0.01 \%$ BAK), and DS (0.0075\%) all affected cell survival compared to control with viabilities of 31,34 , and $52 \%$, respectively $(p=0.0007, p=0.0017$, and $p=0.011)$ (Fig. 1). BT (0.005\% BAK), the lowest percentage of BAK, did not significantly affect cell survival after 30 min or 6 h. There was no significant difference in cell survival between eye drops after $30 \mathrm{~min}$, though BT tended to cause less damage compared to LT, OP, and DS with 22-24\% greater cell survival. After $6 \mathrm{~h}, \mathrm{BT}$ caused $43 \%$ greater cell survival compared to LT $(p=0.036)$. 
Fig. 1. Human conjunctival goblet cell survival after application with eye drops for 30 min or $6 \mathrm{~h}$ assessed by lactate dehydrogenase assay. Values are mean + SD. Brackets indicate significant difference. BT, Brimonidine Tartrate Teva; DS, Dorzolamide Stada; OP, Optimol ${ }^{\circledR}$; LT, Latanoprost Teva; BAK, benzalkonium chloride.
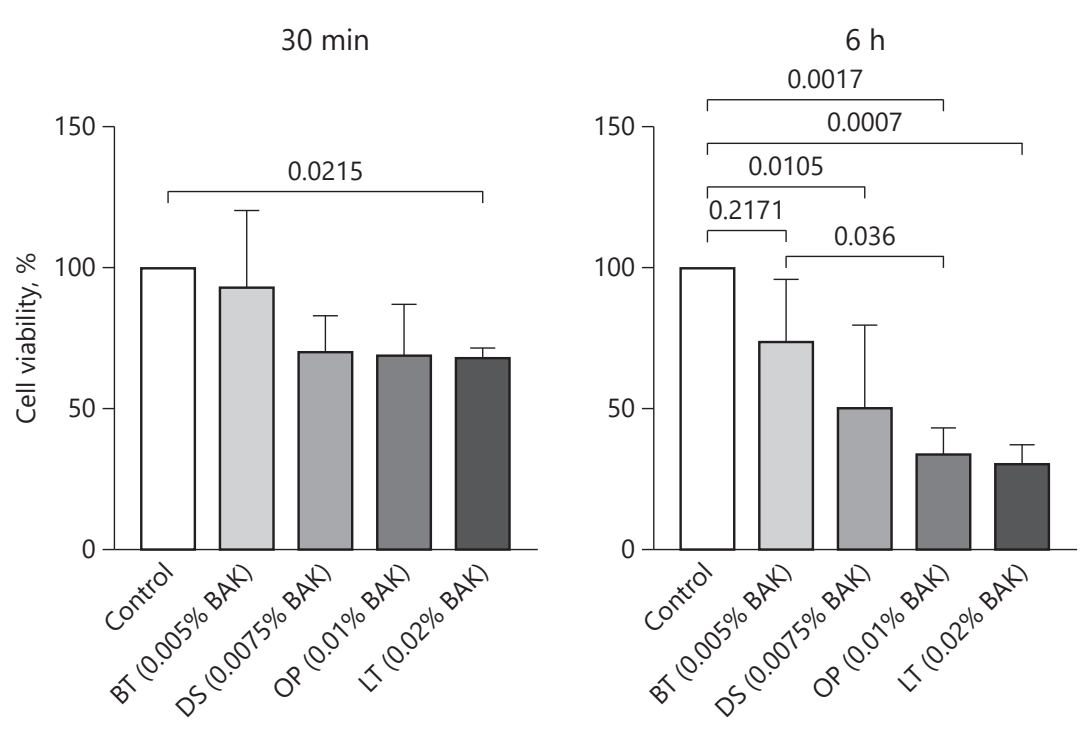

Fig. 2. $\mathrm{pH}$ measurement of eye drops. Values are mean + SD. Brackets indicate significant difference. BT, Brimonidine Tartrate Teva; DS, Dorzolamide Stada; OP, Optimol ${ }^{\circledR}$; LT, Latanoprost Teva.

Fig. 3. Osmolality measurement of eye drops. Values are mean + SD. No significant differences were obtained. BT, Brimonidine Tartrate Teva; DS, Dorzolamide Stada; OP, Optimol ${ }^{\circledR}$; LT, Latanoprost Teva.

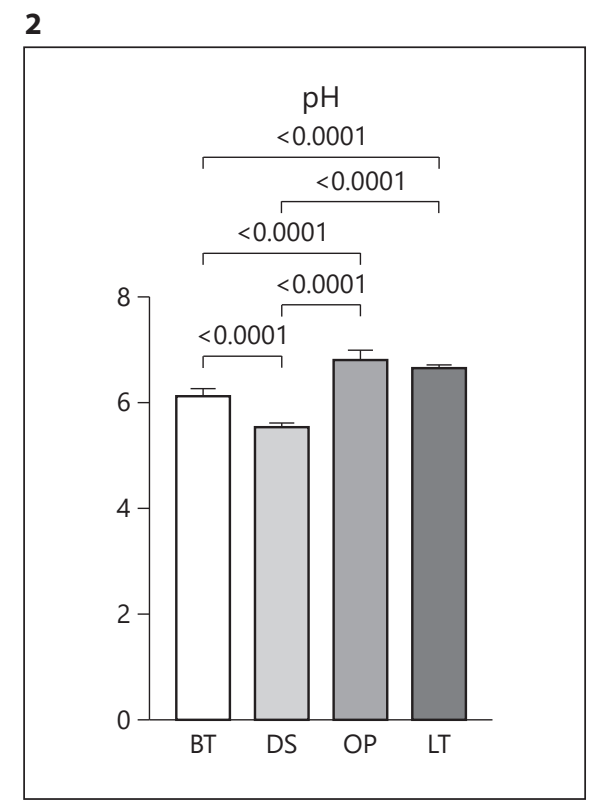

3

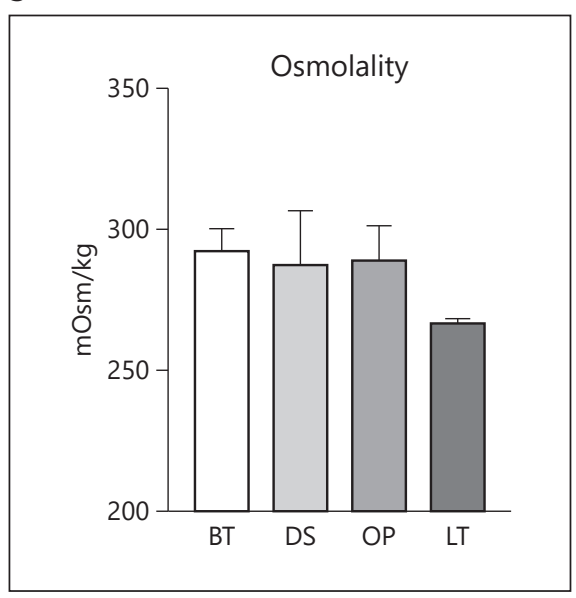

pH Measurement of BAK-Containing Eye Drops

The $\mathrm{pH}$ value was measured in triplicate on 3 different containers for each eye drop. DS had the most acidic $\mathrm{pH}$ of 5.58 and OP the least acidic of 6.84. All eye drops, except LT and OP, differed significantly from each other ( $p$ $\leq 0.001$ ) (Fig. 2). All the eye drops differed significantly from the tear film $\mathrm{pH}$ of $7.6(p<0.001)[16]$.

\section{Osmolality Measurement of BAK-Containing Eye Drops}

The osmolality was measured in triplicate on 3 different containers for each eye drop. None of the eye drops differed significantly from one another (shown in Fig. 3). LT had the lowest osmolality of $267.6 \mathrm{mOsm} / \mathrm{kg}$, and BT had the highest osmolality of $293.2 \mathrm{mOsm} / \mathrm{kg}$. 


\section{Discussion/Conclusion}

In the present study, we found significant impact on human goblet cell survival in a time-dependent manner after treatment with different BAK-preserved IOP-lowering eye drops. Exposure to LT, OP, and DS eye drops demonstrated cytotoxicity, which increased with exposure duration. BT did not affect cell viability. The concentration of BAK may explain the differences in cytotoxicity. All the eye drops contained BAK. The highest BAK concentration of $0.02 \%$ was found in LT, which was also the most toxic, while BT with $0.005 \%$ BAK, the lowest concentration, was not cytotoxic. DS eye drops contained $0.0075 \%$ BAK, and OP eye drops contained $0.01 \%$ BAK. The eye drops, however, had different active components (AA, CAI, PG, and $\mathrm{BB})$, and it is possible that the difference in goblet cell survival was due to the active component and/or the BAK concentration. This cannot be ruled out based on the current study, and further investigation is encouraged. It has, however, previously been demonstrated on cultured corneal and conjunctival epithelial cells that BAK-preserved PG eye drops have similar cytotoxicity as observed in control drops with the corresponding BAK concentrations [14]. These results indicate that the toxicity is due to the preservative and not the active drug. Preservative-free PG even appears to stimulate goblet cell growth [17], and treatment with PG is associated with less treatment failure compared to CAI, miotics, AA, and BB [18].

No previous comparison study has been made on cultured human goblet cells, but comparisons of different preservatives have been performed on human corneal and conjunctival epithelial cells. SofZia and PQ1-preserved PG eye drops were less cytotoxic than BAK alone and BAK-preserved PG eye drops [14]. PQ1-preserved $\mathrm{PG} / \mathrm{BB}$ eye drops were favorable to BAK-preserved PG/ $\mathrm{BB}$ eye drops [19]. In animal models, the BAK-induced damage has also been demonstrated. BAK alone caused reduced goblet cell density and increased corneal staining and inflammation of the ocular surface in mice [20]. Compared to PQ1 and preservative-free drops, BAK increased cell death, expression of inflammatory markers, and corneal damage [21]. In rats, BAK significantly altered the corneoconjunctival surface as evaluated by slitlamp examination, fluorescein staining test, impression cytology, in vivo confocal microscopy, histology, and tear production compared to PQ1. Both BAK and PQ1 caused a significant decrease in goblet cells compared to control [22]. In rabbits, both BAK alone and BAK-preserved eye drops caused a decrease in goblet cell density compared to preservative-free and PQ1- and SofZia-preserved eye

Effect of Anti-Glaucomatous Drugs on Goblet Cells drops [23-25]. With these studies, it is surprising that BAK is still the most used preservative in ophthalmic solutions though safer preservatives and, even better, preservative-free options are available.

Clinical studies have repeatedly concluded that BAK is damaging to the ocular surface, and preservative-free eye drops are found to be favorable with regard to safety and tolerability [26-28]. Goblet cell density decreased when applying preserved eye drops compared to preservative-free drops when assessed by impression cytology and in vivo conjunctival confocal microscopy $[29,30]$. SofZia caused longer tear breakup time and less superficial punctate keratopathy compared to BAK [13], and PQ1 had a better safety profile than BAK [31], though the latter could not be confirmed by Gandolfi et al. [32]. Of note, the efficacy of the drugs does not depend on the presence of preservatives as previously believed [27,31-33]. Most glaucoma patients face lifelong treatment with preserved anti-glaucomatous eye drops and are at risk of developing preservative-induced ocular damage and discomfort. Based on our results and results of previous studies, removal of BAK from the eye drops should be recommended.

Cell viability was assessed with diluted eye drops to mimic dilution in the tear film upon instillation. Upon dilution, the differences in $\mathrm{pH}$ between eye drops diminished with increased values of 7.09-7.33. Osmolality differences also diminished to values of $260.7-278.0 \mathrm{mOsm} /$ $\mathrm{kg}$. Hence, the $\mathrm{pH}$ value and osmolality did not appear to cause the differences in viability. The differences in these parameters in undiluted eye drops used by patients may, however, cause differences in tolerability. A pH value of 5.58 for DS may indeed cause more severe side effects upon instillation than a $\mathrm{pH}$ of 6.84 for OP, as the tear film has an approximate $\mathrm{pH}$ of 7.6 [16]. Hypo- or hyperosmolality can cause disturbances in the tear film, with an osmolality of approximately $302 \mathrm{mOsm} / \mathrm{kg}$ [16], and induce OSD. With the hypoosmolality of 267.6 for LT, though not statistically significant from the remaining eye drops, the risk of OSD may, therefore, be higher than that of BT, with an osmolality of $293.2 \mathrm{mOsm} / \mathrm{kg}$. European Pharmacopeia recommends that the osmolality of ophthalmic preparations range from 270 to $330 \mathrm{mOsm} / \mathrm{kg}$.

A key limitation to this study is that we examined eye drops with different active compounds. Furthermore, the study was performed in vitro. We diluted the eye drops in medium to mimic a dilution in the tear film upon application to the eye. Our test concentrations, however, remained stable during the entire exposure, which would not be the case when applying the drops to the eye. We also diluted in culture medium which does not directly 
correspond the tear film. The buffers in the eye drops may act differently in the tear film than in the culture medium. The $\mathrm{pH}$ and osmolality of the eye drops, when diluted in tear film, may, therefore, be different from what we measured in the drops themselves. Our results cannot be directly transferred to the clinic yet do provide some insight as to which eye drops are cytotoxic.

We conclude that BAK-preserved IOP-lowering eye drops are cytotoxic in a dose-dependent manner making $0.02 \%$ BAK-preserved Latanoprost most toxic and 0.005\% BAK-preserved Brimonidine Tartrate least toxic. Studies on human goblet cell survival when treating with preserved and preservative-free eye drops of the same treatment group would be of interest.

\section{Acknowledgment}

Special thanks are due to the laboratory technician Charlotte Taul for assistance with analyses.

\section{Statement of Ethics}

The protocol complied with the Declaration of Helsinki and was approved by the Danish National Committee on Health Research (H-17007902) and the Norwegian Regional Committees for Medical and Health Research Ethics (REK: 2013/803).

\section{Conflict of Interest Statement}

The authors have no conflicts of interest to declare.

\section{Funding Sources}

The study was funded by The Eye Research Foundation and Fight for Sight, Denmark. R.V. is a part of the Bridge Translational Excellence Program funded by the Novo Nordisk Foundation (Grant Agreement No. NNF18SA0034956). Funding for D.A.D. is from the US NIH grant EY019470.

\section{Author Contributions}

M.K., S.H., G.P., and B.C. contributed to the outline of the study. A.H., X.B., Z.M., and O.M. performed laboratory analyses. R.V. contributed to the setup of the analyses. G.P. provided tissue for cultivation. J.B. instructed in goblet cell culture. A.H. and X.B. performed statistical analyses and wrote the article manuscript. D.A.D. and M.K. helped in manuscript writing. The manuscript has been approved by all authors.

\section{Data Availability Statement}

Data available on request from the authors.

\section{References}

1 Tham YC, Li X, Wong TY, Quigley HA, Aung $\mathrm{T}$, Cheng CY. Global prevalence of glaucoma and projections of glaucoma burden through 2040: a systematic review and meta-analysis. Ophthalmology. 2014;121(11):2081-90.

2 Peters D, Bengtsson B, Heijl A. Factors associated with lifetime risk of open-angle glaucoma blindness. Acta Ophthalmol. 2014;92(5): 421-5.

3 Kolko M. Present and new treatment strategies in the management of glaucoma. Open Ophthalmol J. 2015;9:89-100.

4 Wolfram C, Stahlberg E, Pfeiffer N. Patientreported nonadherence with glaucoma therapy. J Ocul Pharmacol Ther. 2019;35(4):223-8.

5 Schein OD, Muñoz B, Tielsch JM, BandeenRoche K, West S. Prevalence of dry eye among the elderly. Am J Ophthalmol. 1997;124(6): 723-8.

6 Leung EW, Medeiros FA, Weinreb RN. Prevalence of ocular surface disease in glaucoma patients. J Glaucoma. 2008;17(5):350-5.

7 Rouen PA, White ML. Dry eye disease: prevalence, assessment, and management. Home Healthc Now. 2018 Mar/Apr;36(2):74-83.
8 Gipson IK. Goblet cells of the conjunctiva: a review of recent findings. Prog Retin Eye Res. 2016;54:49-63.

9 McCauley HA, Guasch G. Three cheers for the goblet cell: maintaining homeostasis in mucosal epithelia. Trends Mol Med. 2015; 21(8):492-503.

10 Steven DW, Alaghband P, Lim KS. Preservatives in glaucoma medication. Br J Ophthalmol. 2018;102(11):1497-503.

11 Louati Y, Shaarawy T. Controversy: is benzalkonium chloride necessary in antiglaucoma drops? J Curr Glaucoma Pract. 2012 Sep-Dec; 6(3):104-7.

12 Aptel F, Pfeiffer N, Schmickler S, Clarke J, Lavin-Dapena C, Moreno-Montanes J, et al. Non-inferiority of preservative-free versus BAK-preserved latanoprost-timolol fixed combination eye drops in patients with openangle glaucoma or ocular hypertension. J Glaucoma. 2019;28(6):498-506.

13 Aihara M, Oshima H, Araie M; EXTraKT Study Group. Effects of SofZia-preserved travoprost and benzalkonium chloride-preserved latanoprost on the ocular surface: a multicentre randomized single-masked study. Acta Ophthalmol. 2013;91(1):e7-14.

14 Ammar DA, Noecker RJ, Kahook MY. Effects of benzalkonium chloride-preserved, polyquad-preserved, and sofZia-preserved topical glaucoma medications on human ocular epithelial cells. Adv Ther. 2010;27(11):837-45.

15 Shatos MA, Ríos JD, Horikawa Y, Hodges RR, Chang EL, Bernardino CR, et al. Isolation and characterization of cultured human conjunctival goblet cells. Invest Ophthalmol Vis Sci. 2003;44(6):2477-86.

16 Stahl U, Willcox M, Stapleton F. Osmolality and tear film dynamics. Clin Exp Optom. 2012;95(1):3-11.

17 DIS S, Agnifili L, Cecannecchia S, DIG A, Ciancaglini $M$. In vivo analysis of prostaglandins-induced ocular surface and periocular adnexa modifications in patients with glaucoma. In Vivo. 2018;32(2):211-20.

18 Zhou Z, Althin R, Sforzolini BS, Dhawan R. Persistency and treatment failure in newly diagnosed open angle glaucoma patients in the United Kingdom. Br J Ophthalmol. 2004; 88(11):1391-4 
19 Brignole-Baudouin F, Riancho L, Liang H, Nakib Z, Baudouin C. In vitro comparative toxicology of polyquad-preserved and benzalkonium chloride-preserved travoprost/ timolol fixed combination and latanoprost/ timolol fixed combination. J Ocul Pharmacol Ther. 2011;27(3):273-80.

20 Barabino S, Antonelli S, Cimbolini N, Mauro $\mathrm{V}$, Bouzin M. The effect of preservatives and antiglaucoma treatments on the ocular surface of mice with dry eye. Invest Ophthalmol Vis Sci. 2014;55(10):6499-504.

21 Kim JH, Kim EJ, Kim YH, Kim YI, Lee SH, Jung JC, et al. In vivo effects of preservativefree and preserved prostaglandin analogs: mouse ocular surface study. Korean J Ophthalmol. 2015;29(4):270-9.

22 Labbe A, Pauly A, Liang H, Brignole-Baudouin F, Martin C, Warnet JM, et al. Comparison of toxicological profiles of benzalkonium chloride and polyquaternium-1: an experimental study. J Ocul Pharmacol Ther. 2006; 22(4):267-78

23 Lee HJ, Jun RM, Cho MS, Choi KR. Comparison of the ocular surface changes following the use of two different prostaglandin F2 $\alpha$ analogues containing benzalkonium chloride or polyquad in rabbit eyes. Cutan Ocul Toxicol. 2015;34(3):195-202.
24 Liang H, Brignole-Baudouin F, Riancho L, Baudouin C. Reduced in vivo ocular surface toxicity with polyquad-preserved travoprost versus benzalkonium-preserved travoprost or latanoprost ophthalmic solutions. Ophthalmic Res. 2012;48(2):89-101.

25 Kahook MY, Noecker R. Quantitative analysis of conjunctival goblet cells after chronic application of topical drops. Adv Ther. 2008; 25(8):743-51.

26 Misiuk-Hojlo M, Pomorska M, Mulak M, Rekas M, Wierzbowska J, Prost M, et al. The RELIEF study: tolerability and efficacy of preservative-free latanoprost in the treatment of glaucoma or ocular hypertension. Eur J Ophthalmol. 2019;29(2):210-5.

27 Rouland JF, Traverso CE, Stalmans I, Fekih LE, Delval L, Renault D, et al. Efficacy and safety of preservative-free latanoprost eyedrops, compared with BAK-preserved latanoprost in patients with ocular hypertension or glaucoma. $\mathrm{Br}$ J Ophthalmol. 2013;97(2):196-200.

28 Jaenen N, Baudouin C, Pouliquen P, Manni G, Figueiredo A, Zeyen T. Ocular symptoms and signs with preserved and preservativefree glaucoma medications. Eur J Ophthalmol. 2007 May-Jun;17(3):341-9.

29 Mastropasqua L, Agnifili L, Fasanella V, Curcio C, Ciabattoni C, Mastropasqua R, et al.
Conjunctival goblet cells density and preservative-free tafluprost therapy for glaucoma: an in vivo confocal microscopy and impression cytology study. Acta Ophthalmol. 2013; 91(5):e397-405.

30 Frezzotti P, Fogagnolo P, Haka G, Motolese I, Iester M, Bagaglia SA, et al. In vivo confocal microscopy of conjunctiva in preservative-free timolol $0.1 \%$ gel formulation therapy for glaucoma. Acta Ophthalmol. 2014;92(2):e133-40.

31 Lopes JF, Hubatsch DA, Amaris P. Effect of benzalkonium chloride-free travoprost on intraocular pressure and ocular surface symptoms in patients with glaucoma previously on latanoprost: an open-label study. BMC Ophthalmol. 2015;15:166.

32 Gandolfi S, Paredes T, Goldberg I, Coote M, Wells A, Volksone L, et al. Comparison of a travoprost BAK-free formulation preserved with polyquaternium-1 with BAK-preserved travoprost in ocular hypertension or openangle glaucoma. Eur J Ophthalmol. 2012 JanFeb;22(1):34-44.

33 Peace JH, Ahlberg P, Wagner M, Lim JM, Wirta D, Branch JD. Polyquaternium-1-preserved travoprost $0.003 \%$ or benzalkonium chloride-preserved travoprost $0.004 \%$ for glaucoma and ocular hypertension. Am J Ophthalmol. 2015;160(2):266-74.e1. 